\title{
The meaning of PIWI proteins in cancer development (Review)
}

\author{
MONIKA LITWIN ${ }^{1,2}$, ANNA SZCZEPAŃSKA-BUDA ${ }^{1,2}$, \\ ALEKSANDRA PIOTROWSKA ${ }^{3}$, PIOTR DZIĘGIEL ${ }^{3,4}$ and WOJCIECH WITKIEWICZ ${ }^{1}$ \\ ${ }^{1}$ Research and Development Centre, Regional Specialist Hospital in Wrocław; ${ }^{2}$ Research and \\ Development Centre Novasome Sp. z o.o., 51-423 Wrocław; ${ }^{3}$ Department of Histology and \\ Embryology, Wrocław Medical University, 50-368 Wrocław; ${ }^{4}$ Department of Physiotherapy and \\ Occupational Therapy in Conservative and Interventional Medicine, 51-612 Wrocław, Poland
}

Received October 18, 2016; Accepted February 1, 2017

DOI: $10.3892 / 01.2017 .5932$

\begin{abstract}
Cancer is a histologically and genetically heterogeneous population of tumor cells that exhibits distinct molecular profiles determined by epigenetic alterations. P-element-induced wimpy testis (PIWI) proteins in complex with PIWI-interacting RNA (piRNA) have been previously demonstrated to be involved in epigenetic regulation in germline cells. Recently, reactivation of PIWI expression, primarily PIWI-like protein 1 and 2, through aberrant DNA methylation resulting in genomic silencing has been identified in various types of tumors. It has been suggested that the PIWI-piRNA complex contributes to cancer development and progression by promoting a stem-like state of cancer cells, or cancer stem cells (CSCs). It has been identified that CSCs represent the cells that have undergone epithelial-mesenchymal transition (EMT) and acquired metastatic capacities. However, the molecular association between the EMT process and the stem-cell state remains unclear. Further extensive characterization of CSCs in individual types of tumors is required to identify specific markers for the heterogeneous population of CSCs and therefore selectively target CSCs. Previous studies indicate a reciprocal regulation between PIWI proteins and a complex signaling network linking markers characterized for CSCs and transcription factors involved in EMT. In the present review, studies of PIWI function are summarized, and the potential involvement of PIWI proteins in cancer development and progression is discussed.
\end{abstract}

Correspondence to: Dr Monika Litwin, Research and Development Centre Novasome Sp. z o.o., 5 Olsztyńska Street, 51-423 Wrocław, Poland

E-mail: m.litwin@cbr.novasome.pl

Abbreviations: $\mathrm{CD}$, cluster of differentiation; CSCs, cancer stem cells; CTAs, cancer/testis antigens; EMT, epithelial-mesenchymal transition; PIWI, P-element-induced wimpy testis; piRNA, PIWI-interacting RNA

Key words: P-element-induced wimpy testis, PIWI-interacting RNA, cancer stem cells

\section{Contents}

1. Epigenetic alterations in cancer

2. P-element-induced wimpy testis (PIWI) proteins and PIWI-interacting RNAs (piRNAs)

3. PIWI-piRNA in cancer development

4. Characteristics of cancer stem cells (CSCs)

5. EMT in CSC development

6. Conclusions

\section{Epigenetic alterations in cancer}

Cancer has been described as a set of diseases driven by progressive genetic abnormalities, including mutations in tumor suppressor genes, oncogenes and chromosomal abnormalities, and by aberrant epigenetic alterations (1). Epigenetic alterations identified in cancer include global DNA hypomethylation, particularly in repetitive regions, but also in the intronic and the coding regions of genes. These alterations may result in the reactivation of transposons, the loss of chromosomal stability and imprinting patterns. Another epigenetic modification is gene-specific DNA hypermethylation, particularly in promoter regions of tumor suppressor genes, deregulation of histone modification patterns and consequently alterations in gene expression. Additionally, small non-coding RNA (ncRNA) deregulation has been studied in detail in various types of cancer in recent years (1). All these alterations drive the transformation of wild-type cells into highly malignant tumor consisting of neoplastic cells with metastatic potential and unlimited proliferation capacities $(1,2)$.

\section{P-element-induced wimpy testis (PIWI) proteins and PIWI-interacting RNAs (piRNAs)}

Currently, three major classes of small regulatory RNAs have been identified: microRNAs, small interfering RNAs (siRNAs) and piRNAs. The least well investigated class of ncRNAs, piRNAs were originally identified in 2006 as ncRNAs that interacted with PIWI proteins, which are a subclass of the conserved Argonaute family of proteins (3-6). The main characteristics of piRNAs are that they are single-stranded ncRNAs, with an average length of 24-32 nucleotides 
exhibiting highly conserved functions across species $(3,7)$. Notably, unlike other ncRNAs, piRNAs are generated from a small number of long single-stranded RNA precursors, transcribed from distinct transposons referred to as 'piRNA clusters' by a Dicer-independent mechanism $(8,9)$. However, certain piRNAs are also encoded in 3'untranslated regions of intergenic non-coding transcripts and protein-coding genes (10). In Drosophila, piRNAs are primarily derived from intergenic repetitive regions in the genome, including transposable elements. Two models of piRNA biogenesis have been suggested in Drosophila: The primary pathway and the secondary 'ping-pong cycle' (11). Certain characteristics of the biogenesis of piRNAs have also been described in other organisms $(3,4)$. Cloning of piRNAs in Drosophila revealed that this group of small ncRNAs also included repeat-associated siRNAs, which were previously identified in plants (12) and trypanosomes (13).

On the basis of phylogenetic analysis, Argonaute proteins may be divided into two subclasses: The AGO subfamily, based on Arabidopsis thaliana Agol proteins, and the PIWI subfamily, related to Drosophila melanogaster Piwi proteins. The AGO and PIWI subclasses of Argonaute are composed of three characteristic domains: the PIWI-Argonaute-Zwille (PAZ) domain, the middle (MID) domain and the PIWI domain (14) (Fig. 1). The PAZ domain of Argonaute proteins recognizes the $3^{\prime}$ end of the RNA, which, in the case of piRNAs, is invariably modified with a 2'-O-methyl group (15). The MID domain, which is located between the PAZ domain and the PIWI domain, is similar to the glucose/galactose-binding protein and the Lac repressor (16). The primary function of the MID domain is to provide a binding pocket for the phosphorylated 5' end of guide strand RNA. The PIWI domain, which is unique to the AGO protein superfamily, adopts a classical $\mathrm{RNase} \mathrm{H}$ fold, and three residues within the PIWI domain form a catalytic triad (generally Asp-Asp-His) $(14,16)$. A previous study has revealed that PIWI proteins, but not AGO, are arginine-methylated by protein arginine methyltransferase 5 and, as a consequence, symmetric dimethylarginines (sDMAs) at their N-termini are formed (17). Several members of the Tudor-domain-containing proteins (Tudor family proteins) specifically bind to sDMAs and serve a crucial role in PIWI function $(11,18,19)$.

The PIWI protein family is highly conserved in a variety of organisms $(20,21)$. PIWI ortholog expression has been identified in the sponge Ephydatia fluviatilis (EfPiwiA and EfpiwiB), jellyfish (Piwi in Clytia hemisphaerica and Cniwi in Podocoryne carnea), planaria Schmidtea mediterranea (Smedwi-1, -2 and -3), Caenorhabditis elegans (Prg-1 and -2), zebrafish (Ziwi and Zili), D. melanogaster (Piwi, Aub and Ago3), mouse (Miwi, Mili and Miwi2) and humans. There are four human PIWIs: PIWI-like protein 1 (PIWIL1, also known as HIWI), PIWIL2 (HILI), PIWIL4 (HIWI2) and PIWIL3 (HIWI3) (22). The chromosomal location and molecular mass of each PIWI protein is presented in Table I.

Current understanding of PIWI protein function has primarily been the result of loss-of-function studies carried out in mice, D. melanogaster, $C$. elegans and zebrafish. These studies have indicated that the PIWI-piRNA system is involved in germline development, primarily spermatogenesis and maintenance of germline and somatic stem cells $(20,21)$.
Further studies have indicated that the piRNA-PIWI signaling pathway serves a crucial role in transposon repression, epigenetic regulation and translation control (20). The epigenetic role of PIWI proteins in germ and stem cell regulation has been the subject of study in a number of organisms: In Drosophila mutants lacking PIWI genes, the inhibition of germline stem cell renewal and depletion of gametes in males and females were observed (22-24). Homozygous Miwi, Mili and Miwi2 knockout male mice exhibited arrested spermatogenesis, apoptosis of germ cells and decreased testis size (25-27). PIWI-piRNA complexes are involved in maintaining genomic integrity in germline stem cells and have been demonstrated to be critical for silencing transposon regions in the genome by clustering at these elements and by methylating DNA (28).

\section{PIWI-piRNA in cancer development}

The functions of PIWI in the germline have been extensively studied. The expression of the human PIWI protein PIWIL1 has been described primarily in germ cells and hematopoietic stem cells (29). PIWIL1 has been detected in human cluster of differentiation (CD) $34^{+}$hematopoietic progenitor cells, but not in well-differentiated cell populations (29). However, several lines of evidence have indicated that the human PIWI proteins PIWIL1 and PIWIL2 are aberrantly expressed in various types of cancer $(30,31)$. Preliminary studies suggest that overexpression and ectopic expression of PIWIL1 is associated with several types of tumor $(31,32)$. Primarily on the basis of immunohistochemical studies, the increased expression of PIWIL1 has been detected in breast $(33,34)$, esophageal (35), pancreas (36), gastric (37) and endometrial (38) carcinoma. In the majority of cases, increased levels of PIWIL1 were markedly associated with an advanced histological tumor grade, advanced clinical stage and a poorer clinical outcome for patients. Positive staining of PIWIL1 in colorectal cancer tissue has been identified to be a marker of poor prognosis for patients with colorectal cancer (39). Increased expression of PIWIL1 in hepatocellular carcinoma (HCC) was positively correlated with tumor size and metastasis and negatively correlated with survival rates (40). Liu et al (41) detected an increased level of PIWIL1 expression in high-grade squamous intraepithelial lesions and cervical cancer, compared with in wild-type cervical tissue. The alterations in PIWIL1 levels were associated with advanced pathological stage and cisplatin resistance of cancer. In vitro and in vivo studies demonstrated that PIWIL1 upregulation contributes to increased tumorigenesis, resistance to chemotherapeutic drugs, acquisition of self-renewal abilities and elevated expression of stem-cell-related transcription markers including octamer-binding protein 4 (OCT4), homeobox protein NANOG (NANOG) and Polycomb complex protein BMI1 (41). The levels of PIWIL1 protein and transcript were significantly upregulated in intratumor tissue from patients with non-small cell lung cancer (NSCLC), compared with in peritumor tissue (42). In addition, using gain-of-function and loss-of-function strategies, a positive association between the expression of PIWIL1 and proliferation of the NSCLC cell line A549 was identified (42). Cao et al (34) demonstrated that PIWIL1 affects the cell cycle by regulating the expression level of transforming growth factor- $\beta$ receptors, 
cyclin-dependent kinase (CDK) 4, CDK6 and CDK8 in breast cancer (34). PIWIL1 overexpression in colon cancer cell lines promoted proliferation and induced global DNA methylation in vitro (43).

Previous studies have indicated that PIWIL2 may also serve an important role in tumor development. Increased expression of PIWIL2 was identified in breast, cervical, gastric, ovarian, prostate and colorectal cancer $(37,38,44-49)$. PIWIL2 expression has been observed in various stages of breast cancer, and its expression was associated with increased expression of the estrogen receptor and proliferation marker Ki-67, as well as cancer progression $(38,50)$. Increased levels of PIWIL2 have also been observed in testicular seminomas, but not in testicular non-seminoma tumors $(51,52)$. Immunohistochemical analysis of prostate cancer tissues revealed increased expression of PIWIL2 in cancer cells, as compared with in non-tumorous adjacent tissues (48). Using an in vitro model of prostate cancer cell lines, it was demonstrated that silencing the expression of PIWIL2 significantly decreased cell invasion and migration, downregulated the expression of neuronal $(\mathrm{N}-)$ cadherin, protein TWIST (TWIST) and vimentin, and upregulated the expression of epithelial (E-)cadherin, matrix metalloproteinase-9 and factors associated with EMT (48). Increased expression of PIWIL2 in colorectal cancer tissue was significantly associated with a decreased degree of differentiation and invasion, and reduced overall survival time (12 months median survival period, vs. 28 months for patients with low PIWIL2) (49). Significantly increased expression of PIWIL2 was observed in primary tumor of colon cancer and lymph node metastasis compared with in non-tumorous colon tissue. An increased level of PIWIL2 was associated with a decreased degree of differentiation of the tumor and invasion, and a lower 5-year overall survival rate (56.6 vs. $84.3 \%)(51,53)$. PIWIL2 knockdown in colon cancer cells significantly decreased proliferation, migration and colony formation, increased apoptosis in vitro, and decreased tumor cell proliferation in vivo (53). It was suggested that PIWIL2 acts as an oncogene by inhibiting apoptosis and promoting cell proliferation through the signal transducer and activator of transcription/B-cell lymphoma extra-large signaling pathway (51). Our recent study demonstrated a decreased level of PIWIL2 in colon cancer tissue compared with in non-tumorous adjacent tissue (Fig. 2) (54). Furthermore, a marked negative association between PIWIL1 and PIWIL2 was observed in wild-type colorectal tissue (Fig. 2). Similarly, Nikpour et al (55) reported the absence of PIWIL2 expression in several bladder carcinoma cell lines and bladder cancer tissues. These authors suggested that that ectopic expression of PIWIL2 is not essential for the pathogenesis of human bladder carcinoma (55). The contradictory results indicate possible reciprocal regulation between PIWIL1 and PIWIL2 in colon cancer (54).

With regard to other members of the PIWI protein family, PIWIL4 has been identified to be overexpressed in human cervical cancer tissue, as compared with in non-tumorous adjacent tissue (56). Furthermore, the expression of PIWIL4, but not of PIWIL1, PIWIL2 or PIWIL3, was significantly increased in renal cell carcinoma (57). PIWIL2 and PIWIL4 mRNA were expressed at an increased level in various breast cancer cell lines compared with in mammary epithelial
Table I. Chromosomal location and molecular mass of PIWI proteins.

\begin{tabular}{lcc}
\hline Protein & Genomic locus & Molecular mass (kDa) \\
\hline PIWIL1 & $12 \mathrm{q} 24.33$ & 98.5 \\
PIWIL2 & $8 \mathrm{p} 21.3$ & 110 \\
PIWIL3 & $22 \mathrm{q} 11.23$ & 101 \\
PIWIL4 & $11 \mathrm{q} 21$ & 97 \\
\hline
\end{tabular}

PIWI, P-element-induced wimpy testis; PIWIL, PIWI-like.

cells, whereas PIWIL1 and PIWIL3 transcripts were undetectable (19). In the case of gastric cancer, expression of four members of the PIWI protein family was markedly increased in tumor tissue compared with in non-tumorous adjacent tissue (37). Increased expression was associated with advanced clinical tumor-node-metastasis (TNM) classification, advanced T-stage and lymph node metastasis, but only PIWIL1 and PIWIL2 levels were associated with poorer overall survival (37).

piRNAs have not been extensively studied in cancer; however, a limited number of preliminary studies suggest that piRNAs are altered in cancer. A specific piRNA-651 has been demonstrated to be aberrantly overexpressed in various tumors compared with in wild-type tissues $(58,59)$. In NSCLC, a significant increase in piRNA-651 levels was identified to be associated with cancer progression (58). Furthermore, the upregulation of piRNA-651 in A549 lung cancer cells caused a significant increase in cell viability and metastasis, and was associated with the upregulation of cyclin D1 and CDK4 in vivo and in vitro. Inhibition of piRNA-651 in gastric cancer cell lines was associated with decreased cellular proliferation (59). The level of piRNA-823 was positively associated with tumor lymph node metastasis and distant metastasis (60). Conversely, upregulated expression of piRNA-651 was observed in gastric, colon, lung and breast cancer tissues (58-60). Increased levels of piRNA-4987, -20365, -20485 and -20582 were observed in breast tumors compared with in non-cancerous tissues, and were associated with lymph node metastasis (60). In spite of these discrepancies, the detection of piRNAs in blood and cancer tissues may be a valid biomarker for identifying circulating or cancer stem cells within the tumor. Recently, Martinez et al (7) described somatic and malignant expression patterns of numerous piRNAs. They detected that 273 piRNAs of the 20,000 known piRNAs are expressed in somatic non-malignant tissues; in corresponding tumor tissues, they detected a significantly increased number of piRNAs, and expression patterns were identified to be specific to malignancies and their clinical features (7).

A PIWI and piRNA model of function in non-tumorous and cancer tissue has been proposed (Fig. 3). piRNAs, along with abundant expression of PIWI, in germline stem cells regulate transposon silencing through DNA methylation during spermatogenesis. In this way, germline cells (expressing PIWI at an increased level) develop normally into somatic tissues in which PIWI proteins are absent $(28,61)$. However, in cancer cells, PIWI and piRNAs exhibit increased expression, which results 


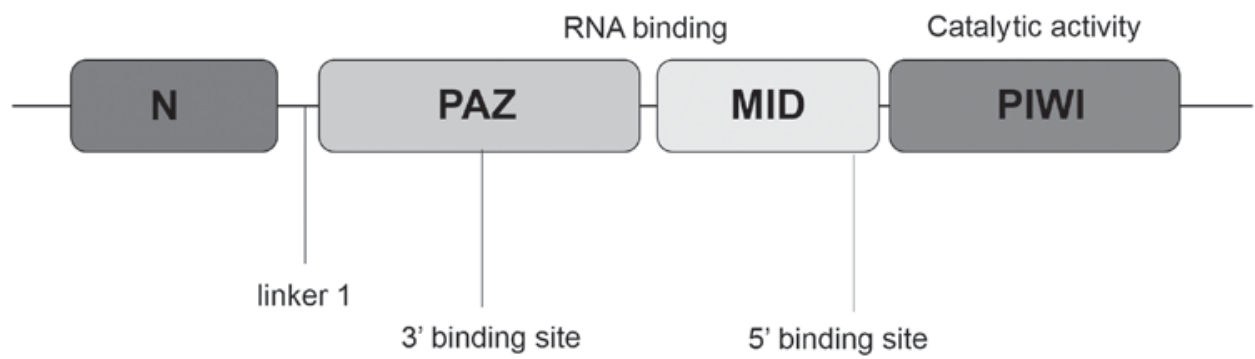

Figure 1. Schematic representation of PIWI proteins. PIWI, P-element-induced wimpy testis; N, N-terminal domain; PAZ, PIWI-Argonaute-Zwille domain; MID, middle domain.
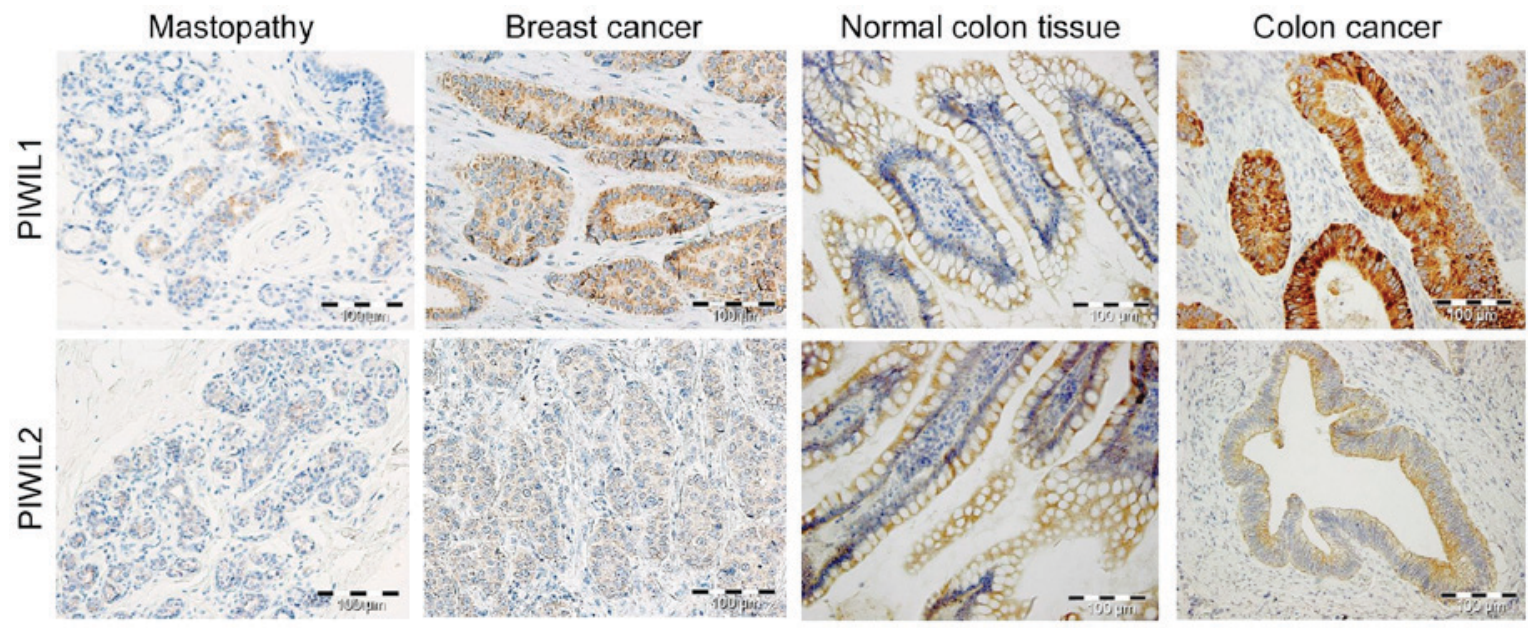

Figure 2. Representative immunohistochemical staining of PIWIL1 and PIWIL2 in colorectal and breast cancer tissue samples together with control mastopathy and non-tumorous colorectal tissue samples. Paraffin blocks were prepared, containing mastopathy and invasive ductal breast carcinoma tissue, derived from patients who underwent surgery and were treated in the Lower Silesian Oncology Center (Wrocław, Poland) between 1999 and 2002 . Paired tissue specimens (tumor and adjacent non-cancerous samples) obtained from patients with colorectal cancer during surgery at the Research and Development Centre, Regional Specialist Hospital (Wrocław, Poland) between 2011 and 2014 were used for immunohistochemical studies. Mastopathy and non-tumorous colorectal tissues were resected from non-malignant tissue adjacent to the primary colorectal and breast tumor.

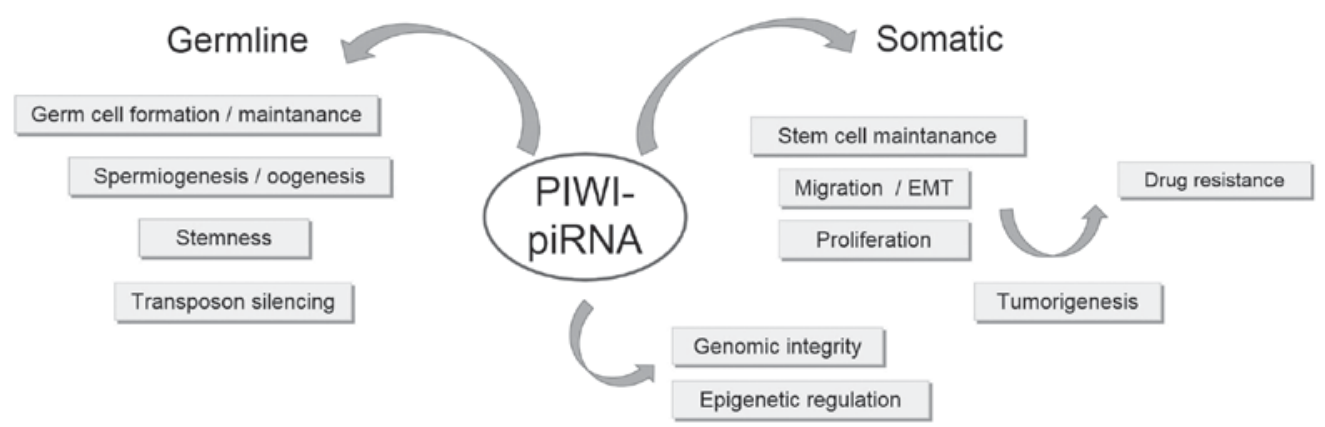

Figure 3. Summary of cellular functions of the PIWI-piRNA signaling pathway. PIWI, P-element-induced wimpy testis; piRNA, PIWI-interacting RNA; EMT, epithelial-mesenchymal transition.

in aberrant DNA methylation, silencing of tumor suppressor genes and an abnormal 'stem-like' state of cancer cells (28). Furthermore, the hypothesis that PIWIL1 and PIWIL2 in cancer contribute to tumorigenesis by transcriptionally silencing tumor suppressor genes through epigenetic mechanisms is supported by observation of their orthologs in mice and $D$. melanogaster (62-66). In mice, Mili and Miwi2 mutants fail to establish de novo DNA methylation of transposon sequences, which is required for transcriptional silencing of transposons in the genome $(62,63)$. It has been suggested that piRNAs acts as a guide for directing transposon-specific DNA methylation (64). In D. melanogaster, Piwi is localized in the nucleus and such subcellular localization determines its function during transposon silencing $(66,67)$. Additionally, PIWI proteins, by suppressing the expression of particular transposons, may be involved in genomic instability, one of the most common alterations to occur in cancer (67). Despite the growing attention on the PIWI-piRNA signaling pathway, only a limited number of studies have described the underlying molecular mechanism by which PIWI proteins contribute to tumorigenesis $(28,61)$. 


\section{Characteristics of cancer stem cells (CSCs)}

Cancer consists of a population of genetically and epigenetically heterogeneous individual cells, exhibiting distinct molecular and phenotypic characteristics, and proliferative potential. Heterogeneity of the tumor cells within the cancer led to the concept of the existence of CSCs, which present epigenetic alterations and signaling pathways characteristic of stem cells, including self-renewal capacity, rapid proliferation and multilineage differentiation $(68,69)$. Although the CSC hypothesis is still evolving, there is evidence to support this model of cancer development and progression (70). Research based on the CSC model has focused on a particular subset of cells that may be explicitly targeted for more effective therapies for cancer $(70,71)$. As numerous so-called cancer/testis antigens (CTAs) that are transiently expressed in developing germ cells have also been identified in various tumors in humans, these may be targets for immunotherapy (71). Due to the restricted expression of PIWI in testis and in various types of tumors, PIWIs may be CTAs. Currently, the most widely used method to identify CSCs is through their expression of particular cell-surface markers called CDs; an example is the antigen CD133, also known as prominin-1, originally classified as a marker of hematopoietic endothelial progenitor cells and neural stem cells (72-74). CD133 is also a marker for organ-specific stem cells and CSCs, and several types of tumor, including brain, hepatocellular, colon, pancreas and prostate (75-79). However, markers expressed exclusively by CSCs currently identified are not specific for cancer stem cells. Therefore, characterization of the genetic and epigenetic alterations that occur in CSCs may provide important insights into the processes of cancer development and metastasis.

To date, certain key signaling pathways have been identified, which may be aberrantly regulated in CSCs, and thus may represent potential targets for cancer diagnostics and therapies $(80,81)$. A number of studies have indicated that several fundamental signaling pathways, including Wnt/ $\beta$-catenin, Notch and Hedgehog, serve critical roles in normal stem cells and CSCs (81). Furthermore, it has been identified that transcription factors OCT4, SRY-box 2 (SOX2), NANOG, Krüppel-like factor 4 (KLF4), c-MYC and LIN28 are responsible for the regulation of pluripotency and self-renewal of embryonic stem cells (ESCs). Expression of these factors, known as ESC markers, is restricted to pluripotent stem cells, downregulated during embryonic development and undetectable in adult wild-type tissues (82). However, alterations in the expression of ESC-associated proteins have been demonstrated in a number of types of cancer: OCT4, also known as POU domain, class 5, transcription factor 1, is expressed in ESCs and adult stem cells, and has been proposed to be associated with the pluripotency, proliferative potential and self-renewal of ESCs and germ cells (83). The transcription factor NANOG, a downstream target of OCT4, which contributes to cell fate determination of the pluripotent inner cell mass during embryonic development, is also specifically expressed in human pluripotent ESCs (82).

Patients with co-expression of OCT4 and NANOG have been demonstrated to exhibit significantly worse overall survival and poor prognosis of several malignancies, including oral (84), glioma (85), gastric (86), rectal (87) and hepatocellular (88) cancer. Overexpression of NANOG was markedly associated with poor prognosis, lymph node metastasis and Dukes' classification of colorectal cancer (89). SOX2, together with OCT4 and NANOG, serves a crucial role in the maintenance of ESC pluripotency. Previous studies have demonstrated that SOX2 is involved in promoting tumorigenesis, proliferation and dedifferentiation of human lung squamous cell carcinoma and breast cancer $(90,91)$. In ovarian cancer, SOX2 expression increases the expression of CSC markers, the potential to form tumor spheres and in vivo tumor-initiating capability. Furthermore, SOX2-expressing cells display enhanced apoptosis resistance in response to conventional chemotherapies (92). In pancreatic carcinoma, alterations in SOX2 were identified to be associated with the invasion and metastatic potential of tumors, suggesting that SOX2 is involved in later events of carcinogenesis (93). In rectal cancer, the increased levels of CD133, OCT4 and SOX2 were significantly associated with tumor recurrence and decreased disease-free survival time (87). Yin et al (88) demonstrated that pluripotent stem cell genes are associated with HCC progression and poor prognosis. Expression of SOX2 and LIN28 in HCC was correlated with an increased tumor size, whereas an increased expression level of c-MYC was associated with vascular invasion (88). An increased level of KLF4 was associated with the aggressiveness of HCC, vascular invasion and cancer differentiation (88). Together with OCT4, SOX2 and C-MYC, KLF4 is a pivotal factor in the generation of induced pluripotent cells and is involved in the epigenetic reprogramming of a somatic genome; KLF4 is required to maintain the cell morphology of mammary epithelial cells (94). Notably, Tiwari et al (95) observed that downregulation of KLF4 induces EMT through alterations in the expression of key genes involved in EMT, including those encoding $\mathrm{N}$-cadherin, vimentin, $\beta$-catenin, vascular endothelial growth factor A and c-Jun N-terminal kinase 1 (95).

PIWI proteins, due to restricted expression during embryonic development and aberrant expression in various types of cancer, have been suggested to act as oncogenes or constitute a marker for CSCs. Reactivated expression of PIWI in cancer and association with certain already defined ESC-associated proteins indicates the participation of these proteins in the process of tumor growth (28). Positive associations between PIWIL1 and OCT4 mRNA levels, as well as PIWIL2 and $S O X 2$, in colon cancer tissues have been identified (54). Thus, the expression of various CSC markers in various types of cancer has been extensively studied; however, the functional characteristics of these markers, co-expression with transcription factors, other signaling pathways and epigenetic mechanisms require further study.

\section{EMT in CSC development}

The alterations in cell motility and adhesiveness, as well as the adaptation to the new microenvironment, observed during tumor growth appear to be crucial in determining the metastatic potential and invasiveness of cancer cells. EMT is a critical process enabling the migration, invasion and metastasis of tumor cells from the primary tumor to distant organs. 
EMT is characterized by long-lasting morphological and molecular alterations in epithelial cells as a result of transdifferentiation towards a mesenchymal cell type (96). During this process, epithelial cells acquire fibroblast-like properties, and demonstrate decreased adhesion and increased motility (96). A number of transcription factors have been implicated in the control of EMT, including zinc-finger protein SNAI1 (SNAI1), TWIST, zinc-finger protein SLUG (SLUG) and zinc-finger E-box-binding homeobox (ZEB) 1 and 2, which directly repress mediators of epithelial cell adhesion, including E-cadherin and components of adherens junctions. In addition, the self-renewal capacity of CSCs appears to be essential for EMT during early steps of metastasis (97-99).

A number of studies have indicated that metastatic cancer cells, which have presumably undergone EMT, may exhibit a CSC-like phenotype: For instance, overexpression of SNAI1, a central transcription factor that regulates EMT, induces a CSC-like phenotype in colorectal cancer cells by directly repressing epithelial markers, including E-cadherin, and by regulating mesenchymal markers (100). SNAI1 upregulation led to increased cell migration and increased metastasis in vivo, and was associated with a more aggressive phenotype, increased rates of distant metastases and poorer clinical outcomes in breast and ovarian carcinoma, and HCC (100). Epithelial breast cancer cells that undergo EMT induced by SNAI1 factor, exhibit CD44-positive and CD24-negative expression, as well as expression of stem-like genes, including NANOG, KLF4 and transcription factor 4 (100). Ectopic expression of OCT4 and NANOG in lung carcinoma was demonstrated to increase the CD133-positive cell subpopulation, activate SLUG, promote EMT and enhance drug resistance (101). Furthermore, double knockdown of OCT4 and NANOG in A549 lung cancer cells suppressed the expression of SLUG, reversed the EMT process, inhibited tumorigenic and metastatic capacities and significantly increased the survival time of transplanted nude mice (101). In nasopharyngeal carcinoma, increased expression of OCT4 and NANOG was significantly associated with a decreased rate of survival (36.1\% 5-year survival rate, compared with 76.7\%) (102). OCT4 and NANOG were primarily located at the invasive front of tumors, and were significantly associated with increased levels of various aggressive clinical factors, and advanced TNM classification and clinical stage; furthermore, these proteins were positively associated with EMT-associated markers (102). The limited effectiveness of standard anticancer therapies has been attributed to the existence of heterogeneous highly drug-resistant populations of CSCs that are responsible for initiation, development and tumor metastasis, as well as response to treatment. Chen et al (103) identified stem-like cancer cells of the colon cancer cell line HCT116 that co-express CD133 and CD44 markers. Cells with increased expression of CD133 and CD44 were undifferentiated, with self-renewal and epithelial lineage differentiation capabilities in vitro, and increased expression of CSC and EMT markers (103). Furthermore, $\mathrm{CD} 133^{+} / \mathrm{CD} 44^{+}$cells represented increased invasive abilities in vitro and increased tumorigenic properties in vivo (103). In addition, alterations in the expression of EMT-associated genes driven by KLF4 downregulation was demonstrated by Tiwari et al (95), as aforementioned.
Yang et al (48) identified that PIWIL2 serves an important role in determining the invasive abilities of prostate cells. The alterations in PIWIL2 expression were associated with alterations in the expression of EMT markers. Silencing the expression of PIWIL2 significantly decreased cell invasion and migration, downregulated the expression of $\mathrm{N}$-cadherin, TWIST and vimentin, and upregulated the expression of E-cadherin, matrix metalloproteinase- 9 and factors associated with EMT (48). In selected breast CSCs characterized by the markers CD44 ${ }^{+}$CD24-, expression levels of PIWIL2 and piRNA-932 were significantly increased in the breast cancer cells that were induced to undergo EMT (104). Furthermore, in head and neck squamous cell carcinoma, increased expression of piRNA-34736 influenced the expression of genes involved in EMT and apoptosis, associated with an advanced tumor stage (105).

\section{Conclusions}

Previous studies have identified a direct connection between stem cell self-renewal and cancer development and invasion (68-70). However, the potential association between CSCs and the PIWI-piRNA signaling pathway remains unexplored. Evidence exists concerning the roles of PIWI proteins in various types of tumors; however, experimental reports, as described, often appear to be contradictory. PIWI proteins in complex with piRNA have been demonstrated to be involved in epigenetic regulation in germline cells by transposon element regulation and in somatic tissue in the activation of gene expression by promoting euchromatic histone modifications and transcription of piRNAs $(106,107)$. Although the number of piRNAs expressed in somatic tissue is significantly lower than in germline cells, tissue specificity associated with the expressed piRNAs has been demonstrated (7).

Aberrant expression of PIWI and piRNAs that target mRNA transcripts may serve a driving role through the degradation or inhibition of tumor suppressor genes or oncogenes (108). Another example of the piRNA-mediated influence on tumorigenesis is by mutagenic retrotranspositions and genomic instability initiation $(107,108)$. PIWI-piRNA complexes contribute to cancer development through aberrant DNA methylation resulting in genomic silencing and promoting a stem-like state of cancer cells $(28,61,108,109)$. A number of studies indicate that stem-like cancer cells represent the cells that have undergone EMT and acquired metastatic capabilities. Our previous study indicates a reciprocal regulation between PIWI proteins and complex signaling network linking markers characterized for CSCs (54) and transcription factors involved in the EMT process; however, further research is required to elucidate the underlying molecular mechanisms.

\section{Acknowledgements}

The present review was partly supported by the Leading National Research Center (KNOW, 2014-2018) of Wrocław Center for Biotechnology and WroVasc Project-Integrated Cardiovascular Centre, co-financed by the European Regional Development Fund within the Innovative Economy Operational Programme 2007-2013 (POIG 1.1-3). 


\section{References}

1. Kanwal R and Gupta S: Epigenetic modifications in cancer. Clin Genet 81: 303-311, 2012.

2. Kristensen LS, Nielsen HM and Hansen LL: Epigenetics and cancer treatment. Eur J Pharmacol 625: 131-142, 2009.

3. Aravin A, Gaidatzis D, Pfeffer S, Lagos-Quintana M, Landgraf P, Iovino N, Morris P, Brownstein MJ, Kuramochi-Miyagawa S, Nakano T, et al: A novel class of small RNAs bind to MILI protein in mouse testes. Nature 442: 203-207, 2006.

4. Girard A, Sachidanandam R, Hannon GJ and Carmell MA: A germline-specific class of small RNAs binds mammalian Piwi proteins. Nature 442: 199-202, 2006.

5. Grivna ST, Beyret E, Wang Z and Lin H: A novel class of small RNAs in mouse spermatogenic cells. Genes Dev 1: 1709-1714, 2006.

6. Watanabe T, Takeda A, Tsukiyama T, Mise K, Okuno T, Sasaki H, Minami N and Imai H: Identification and characterization of two novel classes of small RNAs in the mouse germline: Retrotransposon-derived siRNAs in oocytes and germline small RNAs in testes. Genes Dev 1: 1732-1743, 2006.

7. Martinez VD, Vucic EA, Thu KL, Hubaux R, Enfield KS, Pikor LA, Becker-Santos DD, Brown CJ, Lam S and Lam WL: Unique somatic and malignant expression patterns implicate PIWI-interacting RNAs in cancer-type specific biology. Sci Rep 5: 10423, 2015.

8. Suzuki R, Honda S and Kirino Y: Piwi expression and function in cancer. Front Genet 3: 204, 2012.

9. Luteijn MJ and Ketting RF: PIWI-interacting RNAs: From generation to transgenerational epigenetics. Nat Rev Genet 14: 523-534, 2013.

10. Robine N, Lau NC, Balla S, Jin Z, Okamura K, Kuramochi-Miyagawa S, Blower MD and Lai EC: A broadly conserved pathway generates 3'UTR-directed primary piRNAs. Curr Biol 19: 2066-2076, 2009.

11. Ku HY and Lin H: PIWI proteins and their interactors in piRNA biogenesis, germline development and gene expression. Natl Sci Rev 1: 205-218, 2014.

12. Llave C, Kasschau KD, Rector MA and Carrington JC: Endogenous and silencing associated small RNAs in plants. Plant Cell 14: 1605-1619, 2002

13. Djikeng A, Shi H, Tschudi C and Ullu E: RNA interference in Trypanosoma brucei: Cloning of small interfering RNAs provides evidence for retroposon-derived 24-26 nucleotide RNAs. RNA 7: 1522-1530, 2001.

14. Farazi TA, Juranek SA and Tuschl T: The growing catalog of small RNAs and their association with distinct Argonaute/Piwi family members. Development 135: 1201-1214, 2008.

15. Simon B, Kirkpatrick JP, Eckhardt S, Reuter M, Rocha EA, Andrade-Navarro MA, Sehr P, Pillai RP and Carlopamgno T: Recognition of 2'-O-methylated 3'-end of piRNA by the PAZ domain of a Piwi protein. Structure 19: 172-180, 2011.

16. Jinek M and Doudna JA: A three dimensional view of the molecular machinery of RNA interference. Nature 457: 405-412, 2009

17. Kirino Y, Kim N, de Planell-Saguer M, Khandros E, Chiorean S, Klein PS, Rigoutsos I, Jongens TA and Mourelatos Z: Arginine methylation of Piwi proteins catalysed by dPRMT5 is required for Ago3 and Aub stability. Nat Cell Biol 11: 652-658, 2009.

18. Vagin VV, Wohlschlegel J, Qu J, Jonsson Z, Huang X, Chuma S, Girard A, Sachidanandam R, Hannon GJ and Aravin AA: Proteomic analysis of murine Piwi proteins reveals a role for arginine methylation in specifying interaction with Tudor family members. Genes Dev 23: 1749-1762, 2009.

19. Hashim A, Rizzo F, Marchese G, Ravo M, Taralllo R, Nassa G, Giurato G, Santamaria G, Cordella A, Cantarella C and Weisz A: RNA sequencing identifies specific PIWI-interacting small non-coding RNA expression patterns in breast cancer. Oncotarget 5: 9901-9910, 2014

20. Juliano C, Wang $\mathbf{J}$ and Lin $\mathrm{H}$ : Uniting germline and stem cells: The function of Piwi proteins and the piRNA pathway in diverse organisms. Annu Rev Genet 45: 447-469, 2011.

21. Thomson $\mathrm{T}$ and Lin H: The biogenesis and function PIWI proteins and piRNAs: Progress and prospect. Annu Rev Cell Dev Biol 25: 355-376, 2009

22. Sasaki T, Shiiohama A, Minoshima S and Shimizu N: Identification of eight members of the Argonaute family in the human genome. Genomics 82: 323-330, 2003.

23. Williams RW and Rubin GM: Argonautel is required for efficient RNA interference in Drosophila embryos. Proc Natl Acad Sci USA 99: 6889-6894, 2002.
24. Carmell MA, Xuan Y, Yhang MQ and Hannon HJ: The Argonaute family: Tentacles that reach into RNAi, developmental control, stem cell maintenance, and tumorigenesis. Genes Dev 16: 2733-2742, 2002.

25. Carmell MA, Girard A, van de Kant HJ, Bourc'his D, Bestor TH, de Rooij DG and Hannon GJ: MIWI2 is essential for spermatogenesis and repression of transposons in the mouse male germline. Dev Cell 12: 503-514, 2007.

26. Kuramochi-Miyagawa S, Kimura T, Ijiri TW, Isobe T, Asada N, Fujita Y, Ikawa M, Iwai N, Okabe M, Deng W, et al: Mili, a mammalian member of piwi family gene, is essential for spermatogenesis. Development 131: 839-849, 2004.

27. Deng W and Lin H: Miwi, a murine homolog of piwi, encodes a cytoplasmic protein essential for spermatogenesis. Dev Cell 2: 819-830, 2002

28. Siddiqi S and Matushansky I: Piwis and piwi-interacting RNAs in the epigenetics of cancer. J Cell Biochem 113: 373-380, 2012.

29. Sharma AK, Nelson MC, Brandt JE, Wessman M, Mahmud N, Weller KP and Hoffman R: Human CD34(+) stem cells express the HIWI gene, a human homologue of the Drosophila gene piwi. Blood 97: 426-434, 2001.

30. Tan Y, Liu L, Liao M, Zhang C, Hu S, Zou M, Gu M and Li X: Emerging roles for PIWI proteins in cancer. Acta Biochim Biophys Sin (Shanghai) 47: 315-324, 2015.

31. Qiao D, Zeeman AM, Deng W, Looijenga LH and Lin H: Molecular characterization of hiwi, a human member of the piwi gene family whose overexpression is correlated with seminomas. Oncogene 21: 3988-3999, 2002.

32. Taubert H, Greither T, Kaushal D, Würl P, Bache M, Bartel F, Kehlen A, Lautenschläger C, Harris L, Kraemer K, et al: Expression of the stem cell self-renewal gene Hiwi and risk of tumour-related death in patients with soft-tissue sarcoma. Oncogene 15: 1098-1100, 2007.

33. Wang DW, Wang ZH, Wang LL, Song Y and Zhang GZ: Overexpression of hiwi promotes growth of human breast cancer cells. Asian Pac J Cancer Prev 15: 7553-7558, 2014.

34. Cao J, Xu G, Lan J, Huang Q, Tang Z and Tian L: High expression of piwi-like RNA mediated gene silencing 1 is associated with poor prognosis via regulating transforming growth factor- $\beta$ receptors and cyclin-dependent kinases in breast cancer. Mol Med Rep 13: 2829-2835, 2016.

35. He W, Wang Z, Wang Q, Fan Q, Shou C, Wang J, Giercksky KE, Nesland JM and Suo Z: Expression of HIWI in human esophageal squamous cell carcinoma is significantly associated with poorer prognosis. BMC Cancer 9: 426, 2009.

36. Grochola LF, Greither T, Taubert H, Möller P, Knippschild U, Udelnow A, Henne-Bruns D and Würl P: The stem cell-associated Hiwi gene in human adenocarcinoma of the pancreas: Expression and risk of tumor-related death. Br J Cancer 99: 1083-1088, 2008.

37. Wang Y, Liu Y, Shen X, Zhang X, Chen X, Yang C and Gao H: The PIWI protein acts as a predictive marker for human gastric cancer. Int J Clin Exp Pathol 5: 315-325, 2012.

38. Liu JJ, Shen R, Chen L, Ye Y, He G, Hua K, Jarjoura D, Nakano T, Ramesh GK, Shapiro CL, et al: Piwil2 is expressed in various stages of breast cancers and has the potential to be used as a novel biomarker. Int J Clin Exp Pathol 3: 328-337, 2010.

39. Zeng Y, Qu LK, Meng L, Liu CY, Dong B, Xing XE, Wu J and Shou CC: HIWI expression profile in cancer cells and its prognostic value for patients with colorectal cancer. Chin Med J (Engl) 124: 2144-2149, 2011.

40. Zhao YM, Zhou JM, Wang LR, He HW, Wang XL, Tao ZH, Sun HC, Wu WZ, Fan J, Tang ZY and Wang L: HIWI is associated with prognosis in patients with hepatocellular carcinoma after curative resection. Cancer 118: 2708-2717, 2012.

41. Liu W, Gao Q, Chen K, Xue X, Li M, Chen Q, Zhu G and Gao Y: Hiwi facilitates chemoresistance as a cancer stem cell marker in cervical cancer. Oncol Rep 32: 1853-1860, 2016.

42. Wang Y, Liu J, Wu G and Yang F: Manipulations in HIWI levels exerts influence on the proliferation of human non-small cell lung cancer cells. Exp Ther Med 11: 1971-1976, 2016.

43. Yang L, Bi L, Liu Q, Zhao M, Cao B, Li D and Xiu J: Hiwi promotes the proliferation of colorectal cancer cells via upregulating global DNA methylation. Dis Markers 2015: 383056, 2015.

44. Ye Y, Yin DT, Chen L, Zhou Q, Shen R, He G, Yan Q, Tong Z, Issekutz AC, Shapiro CL, et al: Identification of Piwil2-like (PL2L) proteins that promote tumorigenesis. PLoS One 5: e13406, 2010. 
45. Liu X, Sun Y, Guo J, Ma H, Li J, Dong B, Jin G, Zhang J, Wu J, Meng L and Shou C: Expression of hiwi gene in human gastric cancer was associated with proliferation of cancer cells. Int J Cancer 118: 1922-1929, 2006.

46. He G, Chen L, Ye Y, Xiao Y, Hua K, Jarjoura D, Nakano T, Barsky SH, Shen R and Gao JX: Piwil2 expressed in various stages of cervical neoplasia is a potential complementary marker for p16. Am J Transl Res 2: 156-169, 2010.

47. Chen $\mathrm{C}$, Liu J and $\mathrm{Xu}$ G: Overexpression of PIWI proteins in human stage III epithelial ovarian cancer with lymph node metastasis. Cancer Biomark 13: 315-321, 2013.

48. Yang Y, Zhang X, Song D and Wei J: Piwil2 modulates the invasion and metastasis of prostate cancer by regulating the expression of matrix metalloproteinase-9 and epithelial-mesenchymal transitions. Oncol Lett 10: 1735-1740, 2015.

49. Oh SJ, Kim SM, Kim YO and Chang HK: Clinicopathologic implications of PIWIL2 expression in colorectal cancer. Korean J Pathol 46: 318-323, 2012.

50. Lee JH, Jung C, Javadian-Elyaderani P, Schweyer S, Schütte D, Shoukier M, Karimi-Busheri F, Weinfeld M, Rasouli-Nia A, Hengstler JG, et al: Pathway of proliferation and apoptosis driven in breast cancer stem cells by stem cell protein piwil2. Cancer Res 70: 4569-4579, 2010.

51. Lee JH, Schütte D, Wulf G, Füzesi L, Radzun HJ, Schweyer S, Engel W and Nayernia K: Stem-cell protein Piwil2 is widely expressed in tumors and inhibits apoptosis through activation of Stat3/Bcl-XL pathway. Hum Mol Genet 15: 201-211, 2006.

52. Gainetdinov IV, Skvortsova YV, Stukacheva EA, Bychenko OS, Kondratieva SA, Zinovieva MV and Azhikina TL: Expression profiles of PIWIL2 short isoforms differ in testicular germ cell tumors of various differentiation subtypes. PLoS One 9: e112528, 2014.

53. Li D, Sun X, Yan D, Huang J, Luo Q, Tang H and Peng Z: Piwil2 modulates the proliferation and metastasis of colon cancer via regulation of matrix metallopeptidase 9 transcriptional activity. Exp Biol Med (Maywood) 237: 1231-1240, 2012

54. Litwin M, Dubis J, Arczyńska K, Piotrowska A, Frydlewicz A, Karczewski M, Dzięgiel P and Witkiewicz W: Correlation of HIWI and HILI expression with cancer stem cell markers in colorectal cancer. Anticancer Res 35: 3317-3324, 2015.

55. Nikpour P, Forouzandeh-Moghaddam M, Ziaee SA, Dokun OY, Schulz WA and Mowla SJ: Absence of PIWIL2 (HILI) expression in human bladder cancer cell lines and tissues. Cancer Epidemiol 33: 271-275, 2009 .

56. Su C, Ren ZJ, Wang F, Liu M, Li X and Tang H: PIWIL4 regulates cervical cancer cell line growth and is involved in down-regulating the expression of p14ARF and p53. FEBS Lett 586: 1356-1362, 2012.

57. Al-Janabi O, Wach S, Nolte E, Weigelt K, Rau TT, Stöhr C Legal W, Schick S, Greither T, Hartmann A, et al: Piwi-like 1 and 4 gene transcript levels are associated with clinicopathological parameters in renal cell carcinoma. Biochim Biophys Acta 1842: 686-690, 2014

58. Li D, Luo Y, Gao Y, Yang Y, Wang Y, Xu Y, Tan S, Zhang Y, Duan J and Yang Y: piR-651 promotes tumour formation in non-small cell lung carcinoma through the upregulation of cyclin D1 and CDK4. Int J Mol Med 38: 927-936, 2016.

59. Cheng J, Guo JM, Xiao BX, Miao Y, Jaing Z, Zhou H and Li QN: piRNA, the new non-coding RNA, is aberrantly expressed in human cancer cells. Clinica Chim Acta 412: 1621-1625, 2011

60. Huang G, Hu H, Xue X, Shen S, Gao E, Guo G, Shen X and Zhang X: Altered expression of piRNAs and their relation with clinicopathologic features of breast cancer. Clin Transl Oncol 15: 563-568, 2013

61. Siddigi S, Terry M and Matushansky I: Hiwi mediated tumorigenesis is associated with DNA hypermethylation. PLoS One 7: e33711, 2012

62. Aravin AA, Sachidanandam R, Bourc'his D, Schaefer C, Pezic D, Toth KF, Bestor T and Hannon GJ: A piRNA pathway primed by individual transposons is linked to de novo DNA methylation in mice. Mol Cell 26: 785-799, 2008.

63. Kuramochi-Miyagawa S, Watanabe T, Gotoh K, Totoki Y, Toyoda A, Ikawa M, Asada N, Kojima K, Yamaguchi Y, Ijiri TW, et al: DNA methylation of retrotransposon genes is regulated by Piwi family members MILI and MIWI2 in murine fetal testes. Genes Dev 22: 908-917, 2008.

64. Brennecke J, Malone CD, Aravin AA, Sachidanandam R, Stark A and Hannon GJ: An epigenetic role for maternally inherited piRNAs in transposon silencing. Science 322: $1387-1392,2008$.
65. Saito K, Nishida KM, Mori T, Kawamura Y,Miyoshi K, Nagami T, Siomi H and Siomi MC: Specific association of Piwi with rasiRNAs derived from retrotransposon and heterochromatic regions in the Drosophila genome. Genes Dev 20: 2214-2222, 2006.

66. Saito K: The epigenetic regulation of transposable elements by PIWI-interacting RNAs in Drosophila. Genes Genet Syst 88: 9-17, 2013.

67. van Wolfswinkel JC and Ketting RF: The role of small non-coding RNAs in genome stability and chromatin organization. J Cell Sci 123: 1825-1839, 2010

68. Lobo NA, Shimono Y, Qian D and Clarke MF: The biology of cancer stem cells. Annu Rev Cell Dev Biol 23: 675-699, 2007.

69. Pardal R, Clarke MF and Morrison SJ: Applying the principles of stem-cell biology to cancer. Nat Rev Cancer 3: 895-902, 2003.

70. Islam F, Gopalan V, Smith RA and Lam AK: Translational potential of cancer stem cells: A review of the detection of cancer stem cells and their roles in cancer recurrence and cancer treatment. Exp Cell Res 335: 135-147, 2015.

71. Yao J, Caballero OL, Yung WK, Weinstein JN, Riggins GJ, Strausberg RL and Zhao Q: Tumor subtype-specific cancer-testis antigens as potential biomarkers and immunotherapeutic targets for cancers. Cancer Immunol Res 2: 371-379, 2014.

72. Yin AH, Miraglia S, Zanjani ED, Almeida-Porada G, Ogawa M, Leary AG, Olweus J, Kearney J and Buck DW: AC133, a novel marker for human hematopoietic stem and progenitor cells. Blood 90: 5002-5012, 1997.

73. Salven P, Mustjoki S, Alitalo R, Alitalo K and Rafii S: VEGFR-3 and CD133 identify a population of CD34+lymphatic/vascular endothelial precursor cells. Blood 101: 168-172, 2003.

74. Uchida N, Buck DW, He D, Reitsma MJ, Masek M, Phan TV, Tsukamoto AS, Gage FH and Weissman IL: Direct isolation of human central nervous system stem cells. Proc Natl Acad Sci USA 97: 14720-14725, 2009.

75. Singh SK, Clarke ID, Terasaki M, Bonn VE, Hawkins C, Squire J and Dirks PB: Identification of a cancer stem cell in human brain tumors. Cancer Res 63: 5821-5828, 2003.

76. Suetsugu A, Nagaki M, Aoki H, Motohashi T, Kunisada T and Moriwaki H: Characterization of CD133+ hepatocellular carcinoma cells as cancer stem/progenitor cells. Biochem Biophys Res Commun 351: 820-824, 2006.

77. O'Brien CA, Pollett A, Gallinger S and Dick JE: A human colon cancer cell capable of initiating tumour growth in immunodeficient mice. Nature 445: 106-110, 2007

78. Hermann PC, Huber SL, Herrler T, Aicher A, Ellwart JW, Guba M, Bruns CJ and Heeschen C: Distinct populations of cancer stem cells determine tumor growth and metastatic activity in human pancreatic cancer. Cell Stem Cell 1: 313-323, 2007.

79. Collins AT, Berry PA, Hyde C, Stower MJ and Maitland NJ: Prospective identification of tumorigenic prostate cancer stem cells. Cancer Res 65: 10946-10951, 2005.

80. Klonisch T, Wiechec E, Hombach-Klonisch S, Ande SR, Wesselborg S, Schulze-Osthoff K and Los M: Cancer stem cell markers in common cancers-therapeutic implications. Trends Mol Med 14: 445-460, 2008

81. Takebe N, Miele L, Harris PJ, Jeong W, Bando H, Kahn M, Yang SX and Ivy SP: Targeting Notch, Hedgehog, and Wnt pathways in cancer stem cells: Clinical update. Nat Rev Clin Oncol 12: 445-464, 2015

82. Wang J, Rao S, Chu J, Shen X, Levasseur DN, Theunissen TW and Orkin SH: A protein interaction network for pluripotency of embryonic stem cells. Nature 444: 364-368, 2006.

83. Niwa H, Miyazaki J and Smith AG: Quantitative expression of Oct-3/4 defines differentiation, dedifferentiation or self-renewal of ES cells. Nature Genet 24: 372-376, 2000.

84. Chiou SH, Yu CC, Huang CY, Lin SC, Liu CJ, Tsai TH, Chou SH, Chien CS, Ku HH and Lo JF: Positive correlations of Oct4 and Nanog in oral cancer stem-like cells and high grade oral squamous cell carcinoma. Clin Cancer Res 14: 4085-4095, 2008.

85. Guo Y, Liu S, Wang P, Zhao S, Wang F, Bing L, Zhang Y, Ling EA, Gao J and Hao A: Expression profile of embryonic stem cell-associated genes Oct4, Sox2 and Nanog in human glioma. Histopathology 59: 763-775, 2011.

86. Matsuoka J, Yashiro M, Sakuari K, Kubo N, Tanaka H, Muguruma K, Sawada T, Ohira M and Hirakawa K: Role of the stemness factors Sox 2 , Oct $3 / 4$, and Nanog in gastric carcinoma. J Surg Res 174: 130-135, 2012.

87. Saigusa S, Tanaka K, Toiyama Y, Yokoe T, Okugawa Y, Ioue Y, Miki C and Kusunoki M: Correlation of CD133, OCT4, and Sox2 in rectal cancer and their association with distant recurrence after chemoradiotherpy. Ann Surg Oncol 16: 3488-3498, 2009. 
88. Yin X, Li YW, Jin JJ, Zhou Y, Ren ZG, Qiu SJ and Zhang BH: The clinical and prognostic implications of pluripotent stem cell gene expression in hepatocellular carcinoma. Oncol Lett 5: $1155-1162,2013$

89. Meng HM, Zheng P, Wang XY, Liu C, Sui HM, Wu SJ, Zhou J, Ding YQ and Li J: Overexpression of Nanog predicts tumor progression and poor prognosis in colorectal cancer. Cancer Biol Ther 9: 295-302,2010.

90. Sholl LM, Barletta JA, Yeap BY, Chirieac LR and Hornick JL: Sox 2 protein expression is an independent poor prognostic indicator in stage I lung adenocarcinoma. Am J Surg Pathol 34: 1193-1198, 2010

91. Lengerke C, Fehm T, Kurth R, Neubauer H, Scheble V, Müller F, Schneider F, Petersen K, Wallwiener D, Kanz L, et al: Expression of the embryonic stem cell marker SOX2 in early-stage breast carcinoma. BMC Cancer 11: 42, 2011.

92. Bareiss PM, Paczulla A, Wang H, Schairer R, Wiehr S, Kohlhofer U, Rothfuss OC, Fischer A, Perner S, Staebler A, et al: SOX2 expression associates with stem cell state in human ovarian carcinoma. Cancer Res 73: 5544-5555, 2013.

93. Sanada Y, Yoshida K, Ohara M, Oeda M, Konishi K and Tsutani Y: Histopathological evaluation of stepwise progression of pancreatic carcinoma with immunohistochemical analysis of gastric epithelial transcription factor SOX2: Comparison of expression patterns between invasive components and cancerous or nonneoplastic intraductal components. Pancreas 32: 164-170, 2006.

94. Takahashi K and Yamanaka S: Induction of pluripotent stem cells from mouse embryonic and adult fibroblast cultures by defined factors. Cell 126: 663-676, 2006.

95. Tiwari N, Meyer-Schaller N, Arnold P, Antoniadis H, Pachkov M, van Nimwegen E and Christofori G: Klf4 is a transcriptional regulator of genes critical for EMT, including Jnk1 (Mapk8). PLoS One 8: e57329, 2013.

96. Thiery JP, Aclogue $H$, Huang RY and Nieto MA: Epithelial-mesenchymal transitions in development and disease. Cell 139: 871-890, 2009.

97. Wu CY, Tsai YP, Wu MZ, Teng SC and Wu KJ: Epigenetic reprogramming and post-transcriptional regulation during the epithelial-mesenchymal transition. Trends Genet 28: 454-463, 2012.

98. Esteban MA, Bao X, Zhuang Q, Zhou T, Qin B and Pei D: The mesenchymal-to-epithelial transition in somatic cell reprogramming. Curr Opin Genet Dev 22: 423-428, 2012.
99. Singh A and Settleman J: EMT, cancer stem cells and drug resistance: An emerging role axis of evil in the war on cancer. Oncogene 29: 4741-4751, 2010.

100. Fan F, Samuel S, Evans KW, Lu J, Xia L, Zhou Y, Sceusi E, Tozzi F, Ye XC, Mani SA and Ellis LM: Overexpression of Snail induces epithelial-mesenchymal transition and a cancer stem cell-like phenotype in human colorectal cancer cells. Cancer Med 1: 5-16, 2012.

101. Chiou SH, Wang ML, Chou YT, Chen CJ, Hong CF, Hsieh WJ, Chang HT, Chen YS, Lin TW, Hsu HS and Wu CW: Coexpression of Oct4 and Nanog enhances malignancy in lung adenocarcinoma by inducing cancer stem cell-like properties and epithelial-mesenchymal transdifferentiation. Cancer Res 70: 10433-10444, 2010.

102. Luo W, Li S, Peng B, Ye Y, Deng X and Yao K: Embryonic stem cell markers SOX2, OCT4 and Nanog expression and their correlations with epithelial-mesenchymal transition in nasopharyngeal carcinoma. PLoS One 8: e56324, 2013.

103. Chen KL, Pan F, Jiang H, Chen JF, Pei L, Xie FW and Liang HJ: Highly enriched CD133(+)CD44(+) stem-like cells with CD133(+)CD44(high) metastatic subset in HCT116 colon cancer cells. Clin Exp Metastasis 28: 751-763, 2011.

104. Zhanga H, Renb Y, Xuc H, Pengd D, Duane C and Liua C: The expression of stem cell protein Piwil2 and piR-932 in breast cancer. Surgical Oncol 22: 217-223, 2013.

105. Botchkina IL, Rowehl RA, Rivadeneira DE, Karpeh MS Jr, Crawford H, Dufour A, Ju J, Wang Y, Leyfman Y and Botchkina GI: Phenotypic subpopulations of metastatic colon cancer stem cells: Genomic analysis. Cancer Genomic Proteomics 6: 19-30, 2009.

106.Zou AE, Zheng H, Saad MA, Rahimy M, Ku J, Kuo SZ, Honda TK, Wang-Rodriguez J, Xuan Y, Korrapati A, et al: The non-coding landscape of head and neck squamous cell carcinoma. Oncotarget 7: 51211-51222, 2016.

107. Watanabe T and Lin H: Posttranscriptional regulation of gene expression by Piwi proteins and piRNAs. Mol Cell 56: 18-27, 2014.

108. Moyano M and Stefani G: piRNA involvement in genome stability and human cancer. J Hematol Oncol 8: 38, 2015.

109. Ng KW, Anderson C, Marshall EA, Minatel BC, Enfield KS, Saprunoff HL, Lam WL and Martinez VD: Piwi-interacting RNAs in cancer: Emerging functions and clinical utility. Mol Cancer 15: 5, 2016. 